\title{
Financial Vulnerability and Personal Credit
}

\author{
Adam Gill ${ }^{* 1}$ | Jacob Turton*,,* | Paul Harrald**** | Eleanor Demuth*
}

\begin{abstract}
Financial vulnerability (FV) can be defined as the likelihood that an individual will experience financial hardship (O'Connor et al., 2019). However, due to its unpredictability, financial vulnerability can manifest itself in several ways and can be temporary, sporadic or even permanent. Most individuals will likely be affected by this type of vulnerability at some point in their lives. However, many consumers are ill-prepared for taking on greater financial responsibility due to low levels of financial literacy or low levels of financial capability (Organisation for Economic Cooperation and Development 2017). The COVID-19 pandemic has left many individuals in a highly precarious state, and this has coincided with the phenomenal growth in unsecured lending via BNPL products, attracting the interest of regulators and debt charities alike (StepChange, 2021). Moreover, the FCA has mandated to credit reference agencies that forbearance due to COVID-19 should not affect credit scores, acknowledging such exogenous factors should not detriment consumers (FCA, 2021b).
\end{abstract}

Accordingly, rather than a narrow focus on risk of default, this paper advocates for lenders to take a broader data-led approach to tackling the challenges posed by financial vulnerability due to its latent and transient nature. Earlier identification and intervention when customers are experiencing financial hardship may help prevent default. Firstly, we consider how macro and micro data sources, in combination with emerging theoretical frameworks that conceptualise financial vulnerability, could be used by lenders for earlier identification of vulnerable customers. Secondly, we look at tailored interventions that could help financially vulnerable consumers once they have been identified, with passive and active methods inspired by protective efforts currently underway within the gambling industry. Lastly, when consumers do enter the arrears process, we highlight how lenders have a responsibility to help mitigate cognitive biases and promote behaviours that will help consumers escape perpetual debt.

\section{Introduction}

Vulnerability within the financial industry has been a somewhat neglected topic until recently. The COVID-19 pandemic has highlighted the difficulties that vulnerable individuals face on a day-to-day basis. Despite over $£ 200$ billion of government support programme funding (Partington, 2020), the precarity that vulnerable consumers face persists as the furlough program winds down (CIPD, 2021),

\footnotetext{
1 adam.gill@imaginecurve.com (corresponding author), *Curve Credit Ltd, **UCL
} 
Universal Credit is cut (Partington \& Elgot, 2021), payment holidays come to an end, while energy prices surge (Romei, 2021).

In February 2021, the FCA found that there were 27.7 million people classed as vulnerable in the UK - a figure which has increased $15 \%$ since the beginning of the pandemic (FCA, 2021). Research commissioned by the Vulnerability Registration Service surveyed 2004 UK adults finding that (1) $15 \%$ found it difficult to communicate with organisations and (2) $57 \%$ spent two or more weeks trying to make organisations aware of circumstances surrounding their health. $24.9 \%$ of the population have also been identified as "financially squeezed"; working-age consumers with significant commitments but little provision to deal with income shocks (PFRC, 2019). These consumers are now facing a cost of living squeeze with UK inflation rising to the highest levels since 2011 (Romei, 2021), while the UN is warning that consumer prices are likely to increase further still by $1.5 \%$ next year (Dempsey, 2021). A recent consultation by the FCA has prompted a new Consumer Duty across the financial sector (FCA, 2021a).

Thanks to increased regulatory guidance and pressures, financial industry members are now more cognizant of the responsibility they have to protect customers who use financial services and products from harm. More promising is the fact that out of the 2004 UK adults surveyed by the Vulnerability Registration Service, 64\% indicated they were willing to share more details regarding their vulnerability if asked (Credit Strategy, 2021). Accordingly, it is incumbent upon lenders to step up their efforts in these unprecedented times and ensure that the investment and innovation that the financial industry is experiencing is also mirrored by new and innovative ways to help safeguard customers. Moving beyond a myopic focus on the risk of a consumer defaulting on debt, proactive identification of when a customer is experiencing hardship will allow lenders to take appropriate actions before individuals succumb to deleterious outcomes such as overindebtedness.

\section{Financial Vulnerability}

\section{Defining and Operationalizing}

Consumer vulnerability can be conceptualised as a state of powerlessness resulting from individual characteristics or states. These encompass socioeconomic status, health, cognition, age and life transitions (Baker et al., 2005). However, for the subset of financial vulnerability $(F V)$, there is no consensus within the academic literature regarding a formal measure or definition, which poses problems in operationalizing the concept. Current definitions of FV span the domains of psychology (Shah, Mullainathan, \& Shafir, 2012), marketing (Baker et al., 2005) and economics (Anderloni et al., 2012), although tend to view FV as a dimension of poverty or low income. 
Vulnerability is the susceptibility to experiencing harm, and thus financial vulnerability may be defined as the likelihood that an individual will experience financial hardship (O'Connor et al., 2019). Using this definition, financial vulnerability is the risk of succumbing to hardship, rather than a state of poverty. Accordingly, any individual, regardless of income, can be financially vulnerable. For example, a high-income lawyer may find themselves vulnerable if they lose their job and income, and are unable to meet their financial commitments. Conversely, a low-income manual labourer who can maintain their current lifestyle would be less vulnerable than the lawyer. This distinction of financial vulnerability and financial hardship is necessary to properly distinguish and define the concept of FV.

This more holistic definition of financial vulnerability also aligns with the recommendations from regulatory bodies. According to policymakers in the UK (FCA, 2017) and US (CFPB, 2013), vulnerability encompasses "(1) low education, numeracy or financial literacy, (2) physical disabilities, (3) severe or long-term illnesses, or mental health issues, (4) low income, (5) high debt, (6) caring responsibilities, (7) being either "younger" or "old," (8) lack of English language skills, and (9) impactful changes in personal circumstances, such as a divorce, death of a spouse, or a redundancy". Accordingly, lenders must acknowledge that far from being a small subset of their user base, financial vulnerability can affect almost anyone.

\section{Theoretical Frameworks}

There are emerging frameworks for assessing and identifying financial vulnerability, though further empirical testing is needed to assess their robustness. However, the frameworks below respect the FCA's definition of financial vulnerability and align with the findings suggesting co-morbidity amongst the main drivers of financial vulnerability (FCA, 2017).

\section{Subjective and Objective risk factors framework}

O'Connor et al's (2019) proposal of a more holistic approach to FV includes both subjective (internal) and objective (external) factors. Subjective factors encompass features such as a consumer's financial awareness or confidence. Meanwhile, objective factors include features that can be assessed independently of the consumer, such as credit history and available assets. This four-quadrant approach allows the identification of consumers whose internal FV is misaligned with their objective FV. 
TABLE 1. Objective and Subjective FV risk factors and possible data sources to derive this information from

\begin{tabular}{|c|c|}
\hline OBJECTIVE FACTORS & DATA SOURCES \\
\hline Assets: income, debt, savings & Open Banking \\
\hline $\begin{array}{c}\text { Non-income factors: education, job } \\
\text { security, health insurance }\end{array}$ & $\begin{array}{c}\text { Credit Application Process } \\
\text { Macro Household Wealth Data }\end{array}$ \\
\hline $\begin{array}{c}\text { Credit: access to credit, credit score, } \\
\text { borrowing costs }\end{array}$ & Credit Reference Agencies \\
\hline SUBJECTIVE FACTORS & DATA SOURCES \\
\hline $\begin{array}{c}\text { Financial Awareness: } \text { misunderstanding } \\
\text { or inattention to financial obligations and } \\
\text { over or under-confidence in one's } \\
\text { situation }\end{array}$ & $\begin{array}{c}\text { Financial Literacy Assessment } \\
\text { Financial Self-Efficacy Assessment }\end{array}$ \\
\hline $\begin{array}{c}\text { Personality: self-control, impatience, } \\
\text { money attitudes, financial behaviours }\end{array}$ & $\begin{array}{c}\text { Personality Psychometrics } \\
\text { Predictive Personality Assessment }\end{array}$ \\
\hline
\end{tabular}

The four quadrants of the framework put forward by O'Connor et al (2019) are:

1. Low Subjective FV + Low Objective FV (Vulnerability level low)

2. Low Subjective FV + High Objective FV (Vulnerability level moderate)

3. High Subjective FV + High Objective FV (Vulnerability level high)

4. High Subjective FV + Low Objective FV (Vulnerability level moderate)

Quadrant 1 is the least vulnerable, with individuals possessing high resources, and high financial awareness and confidence. Quadrant 2 is moderately vulnerable, with individuals paying attention to their finances, but lacking the resources to meet financial obligations. Quadrant 3 is highly vulnerable, with low resources and no attention being paid to their finances. Quadrant 4 is also moderately vulnerable, with adequate resources but not paying attention to finances. O'Connor et al (2019) have also suggested differing interventions dependent on each quadrant.

This segmentation strategy allows for easier grouping of customers and tailored interventions depending on which quadrant they reside in, as well as simpler monitoring for escalation and de-escalation of financial vulnerability. Moreover, the increasing availability of affordability data and household wealth surveys should make objective factor data gathering relatively simple. For subjective factors, some interaction and self-reported measures may be required. However, lenders and fintechs may be able to gamify select assessments within their app and look to the 
emerging field of using behavioural data for predictive personality assessment (Gladstone et al., 2019) to overcome these issues.

\section{An integrated measure of financial vulnerability}

An alternative approach to assessing financial vulnerability within the academic literature comes from Hoffmann et al., (2019). Using the US and UK regulatory body recommendations as a guideline, the authors created an integrated measure of FV. FV demographic risk factors such as age, education, disability, changing circumstances and caring responsibilities were collected from participants. Numeracy and financial literacy skills were assessed using existing scales, with English language skills judged on having English as a first language. The financial risk factors put forward by the regulators including low income and debt-to-income ratios were assessed using federal poverty guidelines and lender thresholds concerning debt (Hoffmann et al., 2019). These ten discrete areas then produced a composite FV score ranging from 0 (low financial vulnerability) to 12 (high financial vulnerability).

The authors tested their measure across three studies involving US consumers finding that (1) most participants experienced some form of FV, with many exposed to multiple risk factors simultaneously; (2) FV consists of placing less value on saving money in a sustained manner, generally less goal-oriented behaviour, and being more present-focused; and (3) FV was generally associated with reduced perceptions of financial self-efficacy, less emphasis on long-term outcomes, and lower rates of being a proactive money manager (Hoffmann et al., 2019). While wide-ranging, collecting all of the data proposed in Hoffmann et al.'s (2019) framework will not be feasible for most lenders without severe interruption on the part of customers. However, these findings provide a good basis for identifying the psychological factors that mediate the relationship between financial vulnerability and financial outcomes.

A follow-up study (Hoffmann et al., 2021) used the same integrated FV measure with longitudinal data. Results from this study demonstrated that (1) even a low risk of FV is precarious, with a relatively high likelihood of transitioning to a higher state of FV, and (2) those in a high vulnerability state were entrenched and less likely to transition back to a lower state of vulnerability. $88.4 \%$ of high vulnerability consumers remained at this higher level of vulnerability three months later, while almost half of lower vulnerability consumers experienced higher vulnerability after three months. Though this longitudinal data is welcomed, further research that is truly long-term is vital to fully understand more perpetual states of financial vulnerability.

Testing these theoretical frameworks

Further research is required to test these two models independently, e.g. is financial vulnerability risk binary in high and low states (Hoffmann et al., 2021) or more 
nuanced with varying risk levels in between (O'Connor et al, 2019). We could also consider how these frameworks may interact and complement one another. For example, which objective or subjective factors are most capable of transitioning individuals from a higher to a lower state of financial vulnerability, and where interventions should focus.

\section{Macro Data}

Macro data sources offer a birds-eye view of vulnerability and can act as an initial aggregate indicator that helps inform further actions. For example, a recently onboarded customer could be identified as at increased risk of vulnerability due to living in a postcode with low household wealth, education levels or internet access exacerbating digital exclusion. When corroborated with additional micro-level information such as affordability data, the customer could be then segmented into an appropriate financial vulnerability risk category.

Data from the gambling industry already suggests that men in age groups 18-24 and 25-34, those who live in a deprived area, and ethnic minority groups are at increased risk of harmful gambling (Gamble Aware, 2021) with disproportionate representations in high-cost credit, being overdrawn, and unable to pay off credit card balances in full each month. Accordingly, identifying these sociodemographic characteristics early on will allow for lenders to be better prepared in assisting individual users to ensure their vulnerability and potential for harm does not escalate. Moreover, the increasing availability of data such as OECD compilation of household wealth microdata (OECD, 2013) or Europe's Household Finance and Consumption Survey offers a solution to traditional data problems, at least in developed economies

\section{Household vulnerability framework}

A working paper from the International Monetary Fund (Leika et al., 2017) has incorporated several data sources to create a household vulnerability assessment framework. Some variables within the framework include income levels, debt levels, repayments and obligations, liquid assets and living costs. This data is measured from household surveys and credit registry data. However, the flexibility of the framework offers the best indicators as well as possible proxies that can be used when available data is limited. Moreover, the issue of fragmented data from various sources is solved by extrapolating information to a common reference period, unification of data sources into a merged database, followed by calibration and validation. Stress testing is then conducted to model household vulnerability in a baseline and adverse scenario to observe changes in the percentage of distressed households. Consequently, the framework is applicable in both advanced and developing economies and has been used to assess vulnerability in Namibia, Finland and Luxembourg. 
Financial Vulnerability Index

Alternatively, a recent UK report utilised public data and credit management service information to create a vulnerability index (Financial Vulnerability in the United Kingdom, 2021). The Financial Vulnerability Index (FVI) uses six components to determine a household's ability to manage daily finances and resilience to economic shocks. These six factors include carrying defaulted debt, using alternative financial products, claiming social benefits, lacking emergency savings, holding a high-cost loan, and relying on credit. A relative score of financial vulnerability is provided, offering geographical and temporal comparisons. For example, there was a rapid acceleration of financial vulnerability as the global pandemic started, with households in the North East more likely to be vulnerable than any other UK region. More granularly, households in Blackpool South, Liverpool Walton and Middlesborough were deemed the three most vulnerable constituencies. Moreover, the dataset is also updated intermittently, with the latest update being October 2021.

\section{Machine Learning}

The identification of vulnerability at the macro level requires a different approach to that of the individual level due to increasingly large and complex data sets. Machine learning technologies can be applied to larger data sources such as household data, greatly assisting in assessing household vulnerability at regional and national levels. OECD research has successfully trialled these methods in the US using unsupervised machine learning (Azzopardi et al., 2019). The results show a significant relationship between household net-worth and the size of monthly debt repayments. Though a central regulatory database that all lenders could contribute to would be a welcome addition, the richness of internal lender data, increasing availability of public data, and computational power increases mean it may be feasible for larger lenders to establish their own national and regional level vulnerability assessments.

\section{Micro Data}

More individual-level data is also highly useful for assessing financial vulnerability. The causes and consequences of vulnerability are not solely financial, with physiological and psychological markers and consequences also present. For example, financial difficulties have been shown to reduce cognitive capacity (Schilbach et al., 2016), increase levels of stress (Gathergood, 2012), and promote anxiety, fear and frustration. Moreover, psychological stress prompts a shift to more habitual behaviours (Schwabe \& Wolf, 2009) and shifts people to focus disproportionately on the present (Haushofer \& Fehr, 2014). Also, low financial literacy is prevalent in the financially vulnerable, with a lack of knowledge about one's own situation (regardless of its severity) being associated with negative financial behaviours. Lastly, low levels of financial self-efficacy (the perceived ability to succeed in managing one's financial affairs) have been linked to debt-related products (Farrell et al., 2016), while those with higher self-efficacy are typically more successful in coping with stressful circumstances. Some of these characteristics 
could be identified by analysing interactions with customers via textual and voice analysis, allowing lenders to proactively direct users to appropriate mental health support providers, while also allowing for earlier interventions.

\section{Physiological signs}

Machine learning has been applied to detect anxiety and depression in early childhood with high success rates for detecting internalising disorders (McGinnis et al., 2019). A recent review suggests assessment of stress using speech has enormous potential, albeit some ethical and privacy considerations to contend with (Slavich et al, 2019). Customer call logs which are recorded for quality assurance and legality by lenders could also be analysed to derive these physiological markers and highlight when a customer shows signs of increased vulnerability. Moreover, as customer interactions evolve to mimic traditional messaging apps, offering customers the choice to interact via voice-notes in-app also offers another avenue for data collection and analysis.

If voice analysis is not feasible, transcription of call logs into text offers another means through natural language processing (NLP) (Cambria \& White, 2014). NLP encompasses a set of computational techniques for the automatic analysis and representation of human language. Many customer support tools now offer sentiment analysis which determines the broad positive or negative themes of a customer's message (Borg \& Boldt, 2020). The same technology could be expanded to uncover markers related to vulnerability such as increased stress and anxiety through NLP. Indeed, recent research has used broad NLP techniques identifying how cognitive problems manifest in language whilst identifying at-risk users (Low et al., 2020). These methods offer one solution for the latent issue of financial vulnerability, providing more real-time information on how a customer may interact in a financially vulnerable situation.

Neurodiversity or mental health issues

Additionally, the prevalence of conditions that can result in incapacity combined with the growth of online lending means it is almost certain that among the volume of customers applying for online credit products, some will have mental capacity limitations (PFRC, 2017). While falling under the umbrella of financial vulnerability, mental capacity limitations and neurodiversity pose a unique challenge for lenders. Recent data from Money and Mental Health Policy found that $47 \%$ of their 3000 surveyed loan applicants were unable to consider the advantages and disadvantages of a loan, and $38 \%$ could not remember what they were told about the loan. When establishing the capacity of an individual, the four aspects of decision-making involve (1) understanding, (2) recall, (3) weighing-up, and (4) communicating. Signs of deficits in these areas could be identified if detailed analytics are collected throughout the customer journey. While data captured at the 
online credit application stage is usually used to improve the design of online application 'journeys', utilising it to gather better customer insights could help in detecting decision-making limitations by way of monitoring how customers enter data, use sliders, and navigate their way through application stages. A customer entering their home address incorrectly several times and rushing between help functions could indicate potential difficulties with recall and understanding. A nudge offering chat or video support without interrupting the application process could be the first instance of support, with specialist telephone support as a secondary measure.

\section{Harmful Gambling and Financial Vulnerability}

Due to increased regulatory interest and scrutiny, the domain of gambling has been studied in more depth compared to the concept of financial vulnerability. However, there exist interrelations between harmful financial outcomes for the financially vulnerable, and those who engage in irresponsible gambling and borrowing behaviours. One bank representative interviewed as part of a recent GambleAware report stated: "... there is undoubtedly a correlation between customers that are experiencing gambling harm who then end up in our Collections Teams..." (Gamble Aware, 2021).

Behavioural economics has highlighted the inconsistencies in human decision making when it comes to financial decisions; low rates of savings, failure to take appropriate insurance products and errors in investments (Nicolini \& Cude, 2021). The complexity of stimuli we are exposed to results in reliance on heuristics (mental shortcuts) which are susceptible to biases. When coupled with the internal pressures we face to find cognitive and emotional comfort, and the external demands from societal norms, we are left vulnerable to distorted decision making (Kahneman, 2013).

Moreover, accumulating evidence shows that credit cards do take advantage of cognitive biases with consumers overestimating their ability to repay (Heidhues \& Köszegi, 2010), being surprised by high interest rates (Stango \& Zinman, 2009) and making more indulgent purchases (Thomas \& Seenivasan, 2011). Additionally, newer BNPL products may trigger impulsive consumer behaviours by reducing the time between purchase and consumption through mobile apps; Hundtofte and Gladstone (2017) found that mobile users are more likely to use payday loan products and engage in impulsive behaviours. Accordingly, safeguarding methods used within the gambling domain (Hilbrecht et al., 2020) could also be used to address financial vulnerability more generally. Some passive interventions and principles the personal credit industry may consider following from other domains include conveying information transparently, and helping financially educate consumers to ensure they are fully aware of the products and services they are signing up for. 


\section{Transparency}

One of the primary responsibilities of the gambling industry is to ensure people are aware of what they are signing up for, with sufficient information on the rules and risks of games (Blaszczynski 1993). While the ultimate decision to gamble represents an individual choice, the guiding principle of informed consent must ensure users are cognizant of the chances of winning, risk factors, and the attitudes and beliefs that determine their choice (Meyer et al. 2009).

Within the personal credit industry, however, such transparency is not required. Legal jargon and dense terms and conditions combined with a lack of financial literacy result in many individuals not always fully understanding what products and services they are signing up for. In addition, consumers' cognitive biases exacerbate these issues. For example, research shows exponential growth bias causes a systematic underestimation of interest rates on short-term loans (Stango and Zinman, 2009). Thus, a single indicator of APR interest may not be the ideal way to assist customers in making informed decisions. However, when consumers are presented with more plain English information in a transparent way, it does result in positive outcomes for customers. For example, advice offered to customers explaining that consistently paying off slightly more than minimum each month dramatically reduces total interest was shown to improve repayments above the minimum (Hendy et al., 2021). While lenders may benefit less from interest payments when being more transparent with customers, transparency can help promote sustainable lending behaviour for all parties involved.

\section{Financial Literacy and Education}

In the US, only $57 \%$ of people understand the most basic concepts of personal finance (Klapper, Lusardi, and van Oudheusden 2015). According to the US' Consumer Financial Protection Bureau, (1) 132 million Americans lack savings to cover 3 months of unforeseen expenses, (2) 60 million are underbanked, (3) 24 million people have no bank account, and (4) 50 million adults have insufficient data to create a FICO credit score (CFPB, 2013). Meanwhile, a similar deficit of adequate financial education exists in the UK, with third parties such as MoneySavingExpert having to play a role in promoting financial literacy (White, 2021). Moreover, the COVID-19 pandemic has furthered inequality more generally, with disruption to the education of millions of schoolchildren and university students. Responsible lenders should take it upon themselves to help remedy the chronic lack of financial education which helps perpetuate financial vulnerability.

Financial literacy is having the skills and knowledge to make effective financial decisions with available resources. Interest in financial literacy has surged recently, with more standardised methods to define and measure it, as well as understand its implications for consumer decision making and policy (Nicolini \& Cude, 2021). Financial education and boosting an individual's financial literacy skills offers one method to help instil the skills and knowledge consumers need to make informed 
decisions. Moreover, because emerging research suggests that financial self-efficacy can act as a buffer against succumbing to financial vulnerability in the first place (Hoffmann et al., 2019), educational interventions that improve financial self-efficacy, directly and indirectly, would have a doubly positive effect on educating customers while also protecting them against financial vulnerability. Digital apps offer an interactive way to promote financial literacy through gamification and rewards, an investment that could benefit lenders by encouraging responsible borrowing behaviours.

Some measures that could be used by lenders include the OECD/INFE toolkit (OECD, 2020), an international survey for measuring adult financial literacy. This measure asks seven financial knowledge questions addressing interest paid on a loan, compound interest, risk and return, the definition of inflation, diversification, time value of money and interest plus principal to produce an overall score. Moreover, a self-assessment question asks how someone rates their financial knowledge to that of others in their country, offering comparison between objective and subjective knowledge. Measures like this could be digitized to gather behavioural analytics and prevent deception, and even customised by lenders to assess financial knowledge most pertinent to their products and services.

Debt literacy is one aspect of overall financial literacy and can be defined as the ability to make everyday decisions concerning debt contracts (Lusardi and Tufano, 2015). Experimental research indicates that infographics could be used to improve debt literacy in the short term, with debt literacy growth being $2 / 3$ of entry-level in the experimental group after exposure to a series of four infographics (Porzak et al., 2021). While this was a small study with a specific demographic requiring further generalizability testing, infographic interventions are relatively low cost, can be made interactive within smartphone applications, and are flexible enough to be tailored to suit individuals' preferred learning styles such as visual, verbal or aural. Moreover, the increasing analytics available from smartphone apps means opaque methods of assessment could also be conducted through usage analytics. And while the results from this study show that debt literacy only improved in the short term, presenting such interventions immediately before a credit or loan decision (a just in time approach) would allow utilising the short-term benefits of increased debt literacy post-intervention.

Overall, improving financial literacy amongst consumers should be a central part of any strategy both for transparency and decreasing risk among customers. However, solely practical educational programs are inconclusive in terms of long-term efficacy (Peeters et al. 2018; Schuchardt et al. 2009). Moreover, a recent meta-analysis showed that interventions that are purely focused on skills and knowledge result in minimal changes to financial behaviours, especially among individuals on a low-income (Miller et al. 2015). Moreover, data from the integrated measure of FV (Hoffmann \& McNair, 2019) that the "effects of financial vulnerability on financial 
outcomes can be explained through the negative associations with the psychological characteristic of personal savings orientation". Consequently, financially vulnerable consumers experience more negative financial outcomes partly because they place less value on the merits of proactive saving, as indicated by their personal savings orientation levels. Thus, while educational initiatives do have a place in building and improving basic money management skills, when such skills already exist, emphasising the importance of the value of good saving practices and increasing consumer self-efficacy in financial matters is required to mitigate negative financial outcomes.

\section{Active Interventions}

There will likely be scenarios where more passive forms of intervention such as education will not suffice to prevent financially vulnerable consumers from experiencing greater harm. Indeed, financial vulnerability also involves less proactivity in money management, a perception of having less personal agency over financial matters, and being more present-focused with consideration of immediate vs distant behavioural consequences (Hoffmann \& McNair, 2019). Offering more proactive tools and solutions to customers will help promote a greater sense of financial self-efficacy. Moreover, disruption of an individual's short-term outlook will require more involvement than the previously mentioned passive methods can offer.

\section{Variable Credit Limits}

Credit limits are one area where a greater sense of self-efficacy can be promoted. Traditionally, available credit consists of a fixed amount dependent on the customer's credit bureau information. However, this credit reporting data is a lagged indicator and only shows how often users pay back balances, outstanding or not. A customer may have the ability to pay outstanding balances and loans but be left with very little for basic living expenses. Newer affordability information via Open Banking initiatives is helping to solve this problem. However, even this information is only periodically updated and does not account for the complexities involved in financial decision making. Accordingly, another option that would promote an individual's financial self-efficacy is a variable credit limit. Instead of manually requesting increases and decreases which require approval, an upper threshold could be set under which the user can increase or decrease their available credit freely depending on their needs. After all, the customer will likely have a more updated and better understanding of their personal circumstances in many cases. Just as gambling site operators allow monthly limits to be set, offering customers a greater sense of control and involvement with their finances may be beneficial. For example, financial self-efficacy was found to be one of the strongest predictors of the types and number of financial products held, with higher levels related to more savings and investments and less debt-related products (Farrell et al., 2016). Moreover, a variable credit limit may also help lessen perceptions that this fixed amount is part of an individual's income; inadvertent behaviour that leads to consumers being more likely to engage in impulsive buying (Abrantes-Braga and Veludo-de-Oliviera, 2020). 


\section{Category, Transaction and Merchant Blocks}

The prevailing hypothesis with credit card spending has been that, because of their nature (contactless, future payments etc), they help reduce the pain of buying, thereby increasing expenditure (Lo \& Harvey, 2011). However, emerging neural research offers an alternative hypothesis, suggesting that in addition, credit cards differentially activate the reward network versus cash, increasing the motivation to spend (Banker et al., 2021). One explanation for this may be the result of reinforcement of credit card use and emerging behaviours as people become familiar with credit cards - the UK has one of the highest rates of credit card adoption in the world, with more than $52 \mathrm{~m}$ open accounts (Megaw, 2021). As we move to a cashless society, the barriers to spending are further deteriorating with novel BNPL products. Consumers' fundamental reward mechanisms being exploited while simultaneously reducing the pain of buying could exacerbate problems faced by financially vulnerable consumers, and may require stricter safeguards and tools for consumers to protect themselves.

Many newer fintech cards now offer restrictions that users can toggle themselves such as card freezing and ATM withdrawal blocks. While these measures should be more widely adopted by incumbent lenders, there is room to take this even further. For example, transaction category or merchant-level blocks which users could toggle themselves would again promote a sense of control over their personal finances. Nudges from providers via notifications about recommendations for blocks could also be offered in cases where users are not actively using them. Moreover, allowing users to customise their in-app notifications and sounds after each purchase could help remind them that they have made a purchase. Financial institutions already have the ability to offer these types of blocks to curtail harmful gambling behaviours (Evans et al., 2020), it would be equally as useful in acting as another barrier to frivolous or impulse spending.

\section{Proactive monitoring}

Financial institutions have a unique window into their customers' lives, and significant reach to the UK population (50 million adults have a bank account and debit card while 34 million have a credit card) (UK Finance, 2019). Using traditional credit bureau reports, newer Open Banking data, and a more proactive approach to monitoring customer behaviour will allow for a reduction in financially vulnerable consumers experiencing escalating levels of harm. One example of this holistic strategy being used effectively comes from a report commissioned by the charity GambleAware (Gamble Aware, 2021). Using Open Banking data from Monzo and HSBC, the report highlights how customer spending patterns and behavioural signs could be used to inform practical solutions. For example, erratic behaviours that are not aligned with a customer's previous history could signal something is awry and prompt intervention before the escalation of harm. The indicators used include spending patterns such as high gambling spend relative to income, exponential 
increases, immediately spending incoming money, requests for credit increases, consistently being overdrawn and multiple credit applications. All of these measures could be equally applied to more general impulsive behaviour such as frivolous spending through proactive monitoring. For example, if a patterned exponential increase in consumer spending is found, additional financial incentives or bonuses could be offered for saving money, to improve a customer's future orientation and disrupt short-term outlooks.

\section{Holistic vulnerability scoring}

TABLE 2 How lenders could utilise various data sources for holistic financial vulnerability scoring throughout the customer journey

\begin{tabular}{|c|c|c|}
\hline \multirow{4}{*}{ ONBOARDING } & DATA SOURCES & DATA TYPE \\
\cline { 2 - 3 } & $\begin{array}{c}\text { Macro Household Wealth Data } \\
\text { Financial Vulnerability Index }\end{array}$ & Initial Aggregate Indicator \\
\cline { 2 - 3 } & $\begin{array}{c}\text { Behavioural Analytics from App } \\
\text { Usage at Credit Application Stage }\end{array}$ & Individual-Level Indicators \\
\hline \multirow{4}{*}{ MONITORING } & $\begin{array}{c}\text { Gamified Financial Literacy and } \\
\text { Self-Efficacy Assessments }\end{array}$ & Individual-Level Indicators \\
\cline { 2 - 3 } & $\begin{array}{c}\text { Customer Call, Chat and Email logs } \\
\text { for Textual and Voice Analysis }\end{array}$ & Individual-Level Indicators \\
\cline { 2 - 3 } & $\begin{array}{c}\text { Predictive Personality Assessment } \\
\text { from Financial Behavioural Data }\end{array}$ & Individual-Level Indicators \\
\hline
\end{tabular}

The table above shows how various alternative data sources mentioned earlier could be used holistically by lenders to provide a better indication of financially vulnerable customers. As lenders build their rich data sets and are able to look back on historical data, the antecedents and consequences of financial vulnerability for their customer base should be better understood through predictive modelling.

During onboarding, initial aggregate indicators could be derived from large data sets such as household wealth data, aided by machine learning models. Next, analytics into how customers interact with a lender's app during the credit application process can provide an insight into their mental state e.g signs of neurodiversity.

Throughout the customer relationship, proactive monitoring could be conducted intermittently through in-app gamified assessments in exchange for rewards and incentives. This would help increase important financial skills such as financial literacy and self-efficacy, buffering users against escalating vulnerability (Hoffmann 
et al., 2019) and provide lenders data on customer skills and attitudes towards money, allowing for earlier, tailored interventions.

When interacting with customers, voice and text analysis of all forms of communication offers a rich source for deriving the physiological consequences of financial vulnerability such as increased stress and anxiety (Gathergood, 2012). Moreover, more proactive identification also allows lenders to intervene and direct customers to appropriate support services to minimize escalation of harm.

Lastly, emerging methods of extrapolating personality traits from transactional and behavioural data aided by machine learning (Turton, Gill \& Harrald, 2022) offer a way for lenders to derive customer personality traits which influence financial behaviors (BHPS, 2011; Brown and Taylor, 2014; Frigerio et al., 2020).

\section{Debt Collection and Arrears}

Proactive identification and support offered to financially vulnerable customers will help prevent the escalation of harm and avoid people from falling into arrears. However, when individuals do find themselves in the debt collection process, there are also cognitive biases that lenders must account for, as well as methods that can be used to ensure financially vulnerable consumers are treated fairly to help them recover from arrears.

\section{Debt-account aversion}

Consistent with the idea that people are inclined to break complex tasks into more manageable parts, it has been found that consumers carrying multiple debts also tend to pay off the smallest debts first (Amar et al., 2011). This behaviour of prioritising the smallest value debts is called debt-account aversion; arising because segregated losses are more distressing, despite it being beneficial first to pay off the highest interest debts. (It is possible this also minimises the effect on credit score.) These findings suggest consumer approaches to debt management and consolidation could impede people's ability to rid themselves of debt successfully. For example, a consumer with a $£ 500$ loan with $5 \%$ interest and a $£ 5000$ loan with $15 \%$ interest might be inclined to pay off the smaller value loan first rather than a portion of the larger loan. One proposed explanation is that debt from hedonic purchases reduces the enjoyment of the purchase, whereas this effect is reduced for utilitarian purchases (Besharat et al., 2015). Accordingly, restricting people's ability to pay off smaller debts first and displaying a consistent reminder of the accumulated interest should help customers focus on their highest priority debts. However, the authors note that fully eliminating these biases towards repaying smaller debts first may require more forceful interventions, such as debt counselling or consolidation, where a consumer pays a central point which then allocates their payment to various 
debts and loans. Lenders may consider in-house solutions offered earlier to customers who show signs of escalating vulnerability.

\section{Present-bias}

Present bias is the tendency to give greater importance to short-term payoffs that are available sooner when presented with competing options at a future date. For example, a present-biased person would opt to receive $£ 20$ today rather than $£ 25$ tomorrow (O'Donoghue \& Rabin, 1999. This concept has been suggested as one reason behind household borrowing and persistent consumer debt, where consumers cannot adhere to their self-set debt paydown plans. A recent study (Kuchler \& Pagel, 2021) examined high-frequency transaction data encompassing spending, income, balances and credit limits to infer US consumers' short-term impatience, as well as their self-awareness regarding their time-inconsistent preferences. The findings from this study showed that after receiving their paycheck, more patient individuals (sophisticated) consumed smoothly over their pay cycle, whereas impatient (naive) individuals showed greater consumption immediately after receiving their paycheck. Present bias and increased naivete were associated with worse performance when attempting to adhere to a payment plan, with impatient consumers delaying debt repayments and choosing to consume. This cycle repeats itself each month when delaying for just one more month is perceived as an attractive option once more.

It is recommended that mechanisms that make adherence to long-term commitments, such as payment plans, more attractive to consumers would alleviate present bias to some degree. Moreover, grouping customers as naive or sophisticated regarding their time preference and assessing overall present bias could be one method to identify individuals requiring greater assistance and interventions when in arrears.

\section{Limitations}

This paper looked at how lenders could tackle the latent and transient challenges posed by financial vulnerability with alternative data sources and proactive monitoring to allow earlier interventions. However, these data sources are predominantly digital, and many of the interventions proposed require consumers to be users of smartphone apps or technically savvy enough to engage with them. However, there still remains an element of digital exclusion which also contributes to people becoming and staying financially vulnerable. A lack of engagement and data on these "analogue" customers may make it harder for lenders to utilise the strategies mentioned here (though mobile phone penetration being high is promising). However, an emphasis on Digital Financial Literacy (DFL) (Lyons et al., 2021) could be a precursor to greater financial literacy and inclusion. DFL encompasses basic levels of financial literacy, but also the skills needed to use smartphones and digital apps, conduct digital financial transactions and sufficiently 
protect oneself when using these products and services (Carlin et al., 2019). A unified framework that brings these two separate concepts together has been proposed (Nicolini \& Cude, 2021). Overall, the benefits of financial literacy should not be underestimated by lenders; it is a viable intervention to reduce inequalities in the financial markets and improve financial inclusion (Organisation for Economic Cooperation and Development [OECD], 2015), but also can be one pillar in helping address the challenges posed by financial vulnerability. Though, another challenge that remains is that the early adopters of such DFL initiatives tend to come from high education and income groups, with research from Japan showing lower income groups are significantly less likely to use Fintech services (Yoshino et al., 2020). Accordingly, specialised initiatives aimed at disadvantaged groups specifically may be also required.

\section{Future Research}

The lack of consensus in defining financial vulnerability within the academic literature necessitates further investigation. Alongside definitions put forward by regulatory bodies (CFPB, 2013; FCA, 2017), we suggest that a broader definition of financial vulnerability could include compromised decision making. As discussed earlier, some consequences of vulnerability have physiological and psychological effects (Gathergood, 2012; Schilbach et al., 2016). A person resorting to more habitual behaviours (Schwabe \& Wolf, 2009) in the face of stress and anxiety about their finances-regardless of the severity of the situation (Haushofer \& Fehr, 2014) could make decisions that are not in their best interests. The various cognitive and behavioural biases that certain financial products exploit (Heidhues \& Köszegi, 2010; Stango \& Zinman, 2009; Thomas \& Seenivasan, 2011) could contribute to this impaired decision making process. Accordingly, it may be that greater protections and interventions are needed not just for neurodiverse consumers and those with mental health issues, but people experiencing high levels or risk of financial vulnerability.

\section{Conclusion}

This paper looked at select theoretical frameworks of financial vulnerability, as well as various methods and data sources that could be used by lenders to help identify financially vulnerable consumers. Firstly, utilising household vulnerability assessment and regional information will allow for the initial flagging of those at increased risk of financial vulnerability. Next, as mirrored in the gambling domain, traditional credit bureau and newer Open Banking data can be used more proactively to identify patterns and changes in behaviour. Alternative data sources such as individual-level psychological characteristics could also be collected at the credit application stage to complement this, offering deeper insights into consumer behaviour. This data-led approach will allow for better identification and segmentation of financially vulnerable 
individuals, and tailored interventions that are appropriate for the level of risk of harm that they face. More generally, revamping product and service offerings in ways that pose barriers to harmful behaviours while simultaneously boosting financial literacy and self-efficacy can also help protect consumers from financial vulnerability as the barriers to digital payments fall away. Together, these methods can help lenders eschew the traditional myopic focus on risk of default, and identify when customers are experiencing hardship, allowing for earlier interventions which may prevent default altogether. 


\section{References}

Abrantes-Braga, F. D. M., \& Veludo-de-Oliveira, T. (2020). Help me, I can't afford it! Antecedents and consequence of risky indebtedness behaviour. European Journal of Marketing.

Amar, M., Ariely, D., Ayal, S., Cryder, C. E., \& Rick, S. I. (2011). Winning the Battle but Losing the War: The Psychology of Debt Management. Journal of Marketing Research, 48(SPL), S38-S50.

Anderloni, L., Bacchiocchi, E., \& Vandone, D. (2012). Household financial vulnerability: An empirical analysis. Research in Economics, 66(3), 284-296

Azzopardi, D., Fareed, F., Lenain, P., \& Sutherland, D. (2019). Assessing Household Financial Vulnerability: Empirical evidence from the U.S. using machine learning. https://doi.org/10.1787/75c63aa1-en

Banker, S., Dunfield, D., Huang, A., \& Prelec, D. (2021). Neural mechanisms of credit card spending. Scientific Reports, 11(1). https://doi.org/10.1038/s41598-021-83488-3

Baker, S. M., Gentry, J. W., \& Rittenburg, T. L. (2005). Building Understanding of the Domain of Consumer Vulnerability. Journal of Macromarketing, 25(2), 128-139. https://doi.org/10.1177/0276146705280622

Besharat, A., Varki, S., \& Craig, A. W. (2015). Keeping consumers in the red: Hedonic debt prioritization within multiple debt accounts. Journal of Consumer Psychology, 25(2), 311-316.

Blaszczynski, A., Ladouceur, R., \& Shaffer, H. J. (2004). A Science-Based Framework for Responsible Gambling: The Reno Model. Journal of Gambling Studies, 20(3), 301-317. https://doi.org/10.1023/b:jogs.0000040281.49444.e2

Borg, A., \& Boldt, M. (2020). Using VADER sentiment and SVM for predicting customer response sentiment. Expert Systems with Applications, 162, 113746.

British Household Panel Survey (BHPS) - Institute for Social and Economic Research (ISER). (2011). Essex.ac.uk. https://www.iser.essex.ac.uk/bhps

Brown, S. and Taylor, K. (2014) Household Finances and the 'Big Five' Personality Traits. Journal of Economic Psychology, 45. pp. 197-212. ISSN 0167-4870

Cambria, E., \& White, B. (2014). Jumping NLP curves: A review of natural language processing research. IEEE Computational intelligence magazine, 9(2), 48-57.

Carlin, B., Olafsson, A., \& Pagel, M. (2019, May). Generational differences in managing personal finances. In AEA Papers and Proceedings (Vol. 109, pp. 54-59).

CIPD. (2021). Coronavirus (COVID-19): Post-furlough guide. https://www.cipd.co.uk/knowledge/fundamentals/emp-law/employees/post-furlough

Consumer Financial Protection Bureau. 2013. Empowering Low Income and Economically Vulnerable Consumers.http://files.consumerfinance.gov/f/201311_cfpb_report_empowering-economicallyvulnerab le-consumers.pdf. 
Credit Strategy. (2021). 64\% of vulnerable customers would share data to central system. https://www.creditstrategy.co.uk/news/news/64-of-vulnerable-customers-would-share-data-to-central-s ystem-19728

Dempsey, H. (2021, November 18). High shipping costs to push up global inflation, UN warns. @FinancialTimes; Financial Times. https://www.ft.com/content/986731f0-8eff-4e0f-8353-eda2ed2bc366

Evans, J., Collard, S. and Fitch, C., 2020, A blueprint for bank card gambling blockers. [pdf] Available at https://www.begambleaware.org/media/2217/bri-uni-gambling-a4-06 072020 final report.pdf

Farrell, L., Fry, T. R. L., \& Risse, L. (2016). The significance of financial self-efficacy in explaining women's personal finance behaviour. Journal of Economic Psychology, 54, 85-99. https://doi.org/10.1016/j.joep.2015.07.00

FCA (2017). Credit card market study: Persistent debt and earlier intervention remedies - feedback on CP17/10 and further consultation. Consultation Paper CP17/43. London: Financial Conduct Authority. Retrieved from https://www.fca.org.uk/publication/consultation/cp17-43.pdf

FCA. (2021, February 11). FCA finds the Covid-19 pandemic leaves over a quarter of UK adults with low financial resilience. https://www.fca.org.uk/news/press-releases/fca-finds-covid-19-pandemic-leaves-over-quarter-uk-adult s-low-financial-resilience

FCA. (2021a). A new Consumer Duty. Feedback to CP21/13 and further consultation. https://www.fca.org.uk/publication/consultation/cp21-36.pdf

FCA. (2021b, April 15). Coronavirus linked forbearance: key findings. https://www.fca.org.uk/publications/multi-firm-reviews/coronavirus-linked-forbearance-key-findings

Financial Vulnerability in the United Kingdom. (2021). Urban. https://apps.urban.org/features/uk-financial-vulnerability-index/financial-vulnerability-in-the-united-king dom.pdf

Frigerio, M., Ottaviani, C., \& Vandone, D. (2020). A meta-analytic investigation of consumer over-indebtedness: The role of impulsivity. International Journal of Consumer Studies, 44(4), 328-342. https://doi.org/10.1111/iics.12570

Gamble Aware. (2021). GAMBLING, VULNERABILITY AND FCA COMPLIANCE. https://www.begambleaware.org/sites/default/files/2021-07/Gambling-vulnerability-FCA-compliance-M AIN-FINAL.pdf

Gathergood, J (2012) Self-control, financial literacy and consumer overindebtedness. JOURNAL OF ECONOMIC PSYCHOLOGY Volume 33 Issue 3 Pages 590-602

Haushofer, J., \& Fehr, E. (2014). On the psychology of poverty. Science, 344(6186), 862-867. https://doi.org/10.1126/science.1232491

Gladstone, J. J., Matz, S. C., \& Lemaire, A. (2019). Can Psychological Traits Be Inferred From Spending? Evidence From Transaction Data. Psychological Science, 30(7), 1087-1096. https://doi.org/10.1177/0956797619849435

Haushofer, J., \& Fehr, E. (2014). On the psychology of poverty. science, 344(6186), 862-867. 
Heidhues, P., \& Kőszegi, B. (2010). Exploiting naivete about self-control in the credit market. American Economic Review, 100(5), 2279-2303.

Hendy, P., Slonim, R., \& Atalay, K. (2021). Unsticking credit card repayments from the minimum: Advice, anchors and financial incentives. Journal of Behavioral and Experimental Finance, 30, 100505.

Hilbrecht, M., Baxter, D., Abbott, M., Binde, P., Clark, L., Hodgins, D. C., ... \& Williams, R. J. (2020). The Conceptual Framework of Harmful Gambling: A revised framework for understanding gambling harm. Journal of Behavioral Addictions, 9(2), 190-205.

Hoffmann, A. O. I., \& McNair, S. J. (2019). How Does Consumers' Financial Vulnerability Relate to Positive and Negative Financial Outcomes? The Mediating Role of Individual Psychological Characteristics. Journal of Consumer Affairs, 53(4), 1630-1673. https://doi.org/10.1111/joca.12233

Hoffmann, A., McNair, S., \& Pallant, J. (2021). The financial vulnerability trap: using latent transition analysis to explore the dynamics of consumers' financial vulnerability over time. European Journal of Marketing.

Hundtofte and Gladstone (2017 Hundtofte, S., and J. Gladstone. 2017. "Who Uses a Smartphone for Financial Services? Evidence of a Selection for Impulsiveness from the Introduction of a Mobile FinTech App". Working Paper.

Kahneman, D. (2013). Thinking, Fast and Slow (1st ed.). Farrar, Straus and Giroux.

Klapper, Leora, Annamaria Lusardi, and Peter van Oudheusden. 2015. Financial Literacy Around the World: Insights from the Standard \& Poor's Ratings Services Global Financial Literacy Survey. https://responsiblefinanceforum.org/wp-content/uploads/2015/12/2015-Finlit paper 17 F3 SINGLES. pdf.

Kuchler, T., \& Pagel, M. (2021). Sticking to your plan: The role of present bias for credit card paydown. Journal of Financial Economics, 139(2), 359-388.

Leika, M., \& Marchettini, D. (2017). A generalized framework for the assessment of household financial vulnerability. International Monetary Fund.

Lo, H.-Y., \& Harvey, N. (2011). Shopping without pain: Compulsive buying and the effects of credit card availability in Europe and the Far East. Journal of Economic Psychology, 32(1), 79-92. https://doi.org/10.1016/j.joep.2010.12.002

Low, D. M., Rumker, L., Talkar, T., Torous, J., Cecchi, G., \& Ghosh, S. S. (2020). Natural Language Processing Reveals Vulnerable Mental Health Support Groups and Heightened Health Anxiety on Reddit During COVID-19: Observational Study. Journal of Medical Internet Research, 22(10), e22635. https://doi.org/10.2196/22635

Lyons, A. C., \& Kass-Hanna, J. (2021). A methodological overview to defining and measuring "digital" financial literacy. Financial Planning Review, e1113.

McGinnis, E. W., Anderau, S. P., Hruschak, J., Gurchiek, R. D., Lopez-Duran, N. L., Fitzgerald, K., Rosenblum, K. L., Muzik, M., \& McGinnis, R. S. (2019). Giving Voice to Vulnerable Children: Machine Learning Analysis of Speech Detects Anxiety and Depression in Early Childhood. IEEE Journal of Biomedical and Health Informatics, 23(6), 2294-2301. https://doi.org/10.1109/jbhi.2019.2913590 
Megaw, N. (2021, September 17). Will Covid and Klarna kill the credit card? @FinancialTimes; Financial Times. https://www.ft.com/content/22c81ad9-91d9-4f00-8b66-1fa77468690d

Meyer (2009). Problem Gambling in Europe: Challenges, prevention, and interventions. International Gambling Studies, 9(2), 179-180. https://doi.org/10.1080/14459790903058983

Money and Mental Health Policy Institute. (2021, June 16). Money and Mental Health Policy Institute. https://www.moneyandmentalhealth.org/

Nicolini, G., \& Cude, B. J. (Eds.). (2021). The Routledge Handbook of Financial Literacy. Routledge.

O'Connor, G. E., Newmeyer, C. E., Wong, N. Y. C., Bayuk, J. B., Cook, L. A., Komarova, Y., ... \& Warmath, D. (2019). Conceptualizing the multiple dimensions of consumer financial vulnerability. Journal of Business Research, 100, 421-430.

O'Donoghue, T., \& Rabin, M. (1999). Doing it now or later. American economic review, 89(1), 103-124.

OECD. 2013. OECD Guidelines for Micro Statistics on Household Wealth, Paris.

Organisation for Economic Co- operation and Development. (2015). National strategies for financial education.

OECD/ INFE Policy Handbook. www.oecd.org/ daf/ fin/ financial- education/ National- Strategies-

Financial- Education- Policy- Handbook.pdf

Organisation for Economic Cooperation and Development. 2017. Household Savings Forecast. https://data.oecd.org/hha/household-savings-forecast.htm.

Organisation for Economic Co- operation and Development. (2020). OECD/ INFE 2020

International Survey of Adult Financial Literacy. www.oecd.org/ financial/ education/ launchoftheoecd Infeglobalfinancialliteracysurveyreport.htm

Partington, R. (2020, September 8). Coronavirus bill has cost UK government £210bn, spending watchdog says. The Guardian; The Guardian. https://www.theguardian.com/politics/2020/sep/08/uks-public-spending-watchdog-estimates-210bn-co ronavirus-bill

Partington, R., \& Elgot, J. (2021, October 27). Budget 2021: Sunak softens universal credit cuts to tackle squeeze on families. The Guardian; The Guardian. https://www.theguardian.com/uk-news/2021/oct/27/budget-2021-rishi-sunak-universal-credit-alcohol-f $\underline{\text { uel-duties }}$

Peeters, Nele, Kathinka Rijk, Barbara Soetens, Berenice Storms, and Koen Hermans. 2018. A Systematic Literature Review to Identify Successful Elements for Financial Education and Counseling in Groups. Journal of Consumer Affairs, 52 (2): 415-440.

PFRC. (2017). Vulnerability: a guide for lending. University of Bristol. https://www.bristol.ac.uk/media-library/sites/geography/pfrc/pfrc1703vulnerability-guide-for-len ding-(web).pdf

PFRC. (2019). Open Banking For Good: Moving The Dial? https://static1.squarespace.com/static/5b3b35d95b409b6cfd1c9ad6/t/6076c1779a3ed37d3799555e/1 618395546708/OB4G Making+a+difference.pdf 
Romei, V. (2021, November 17). UK inflation rises to highest level since 2011. @FinancialTimes; Financial Times. https://www.ft.com/content/1d3d1cfb-e0af-42db-b1d8-1f601854ea8d

Schilbach, F., Schofield, H., \& Mullainathan, S. (2016). The Psychological Lives of the Poor. American Economic Review, 106(5), 435-440. https://doi.org/10.1257/aer.p20161101

Schuchardt, Jane, Sherman D. Hanna, Tahira K. Hira, Angela Lyons, Lance Palmer, and Jing Jian Xiao. 2009. Financial Literacy and Education Research Priorities. Journal of Financial Counseling and Planning, 20 (1): 84-95.

Schwabe, L., \& Wolf, O. T. (2009). Stress Prompts Habit Behavior in Humans. Journal of Neuroscience, 29(22), 7191-7198. https://doi.org/10.1523/ineurosci.0979-09.2009

Shah, A. K., Mullainathan, S., \& Shafir, E. (2012). Some consequences of having too little. Science, 338(6107), 682-685.

Slavich, G. M., Taylor, S., \& Picard, R. W. (2019). Stress measurement using speech: Recent advancements, validation issues, and ethical and privacy considerations. Stress, 22(4), 408-413.

Stango, V., \& Zinman, J. (2009). Exponential growth bias and household finance. The Journal of Finance, 64(6), 2807-2849.

UK Finance (2019). UK payment markets summary 2019. Available at https://www.ukfinance.org.uk/sites/default/files/uploads/pdf/UK-Finance-UKPayment-Markets-Report2019-SUMMARY.pdf

StepChange. (2021). StepChange reaction to HM Treasury BNPL consultation. https://www.stepchange.org/media-centre/press-releases/buy-now-pay-later-consultation.aspx

Thomas, M., Desai, K. K., \& Seenivasan, S. (2011). How credit card payments increase unhealthy food purchases: Visceral regulation of vices. Journal of consumer research, 38(1), 126-139.

Turton, J., Gill, A \& Harrald, P. (2022). Measuring Personality For Credit Eligibility: Approaches and Challenges

White, E. (2021, October 25). First-ever financial education textbook now available across the UK. MoneySavingExpert.com; MoneySavingExpert.com News. https://www.moneysavingexpert.com/news/2021/10/first-ever-financial-education-textbook-arrives-inwelsh-schools/

Yoshino, N., Morgan, P. J., \& Trinh, L. Q. (2020). Financial literacy and fintech adoption in Japan (ADBI

Working Paper 1095). www.adb.org/ publications/ financial- literacy- fintech- adoption- japan 